\title{
Fermilab
}

TM-1137

1183.000

Sept. 1982

\section{Proton Therapy Nozzles Design and Analysis}

\author{
S. L. Kramer
}

Argonne National Laboratory

\section{Introduction}

Beams from high energy accelerators are constrained to have very small emittances. To be useful for large volume proton therapy they must be spread out in space to 111 uminate the entrance portal uniformly. This could be done by letting the beam diverge (either from its own angular spread or by defocusing it with quadrupoles) and then collimating the beam to a uniformity of the spatial density of particles to yield the required dose uniformity. However, this technique is very inefficient on the use of incident beam.

Although scanning the beam magnetically could yield high efficiency and highly uniform dose, 1 considerable development would be necessary to develop the technique and its required reliability. The use of multiple scattering folls simplifies the treatment planning and verification, since the size and uniformity is determined only by the properties of the materials and not by the variables (current, temperature, hysteresis, etc.) in magnetic scanning devices. 


\section{Multiple Scattering of High Energy Protons}

Although an accurate description of the multiple scattering distribution is quite complex, ${ }^{2}$ considerable simplification can be made by assuming a Gaussian distribution in $r$

$$
f(r) \operatorname{rdrd} \phi=\frac{1}{\pi R^{2}} \operatorname{EXP}\left[-\left(\frac{r}{R}\right)^{2}\right] \operatorname{rdrd} \phi
$$

where $\quad R=$ the root-mean-square radius of particle density measured a distance $\mathrm{Z}$ from the foil.

This distribution yields the probability that a proton is a pencil beam of particles will be scattered into an area $\operatorname{rdrd} \phi$, transverse to the beam. The parameter $R$ can be expressed in terms of an rms scatter angle $\left\langle\theta^{2}\right\rangle^{1 / 2}$ by

$$
\mathrm{R}=\mathrm{Z}\left\langle\theta^{2}\right\rangle 1 / 2
$$

For a differential thickness of material, dX, the mean square scatter angle is given approximately ${ }^{3}$ by

$$
d \theta^{2}=\left(\frac{E}{p \beta}\right)^{2} \frac{d X}{X_{R}}
$$


where

$$
\begin{aligned}
& \mathrm{p}=\text { the momentum of the proton } \\
& \beta=\text { the velocity factor } \\
& \mathrm{X}_{\mathrm{R}}=\text { the radiation length of the material and } \\
& \mathrm{E}_{\mathrm{S}}=\text { a constant of the material }(\approx 17 \text { to } 21 \mathrm{MeV} / \mathrm{c} \text { depending on } \mathrm{Z}, \\
& \quad \text { value used }=20 \mathrm{MeV} / \mathrm{c})
\end{aligned}
$$

For thick foils the mean square scatter angle is

$$
\left\langle\theta^{2}\right\rangle=\frac{E_{s}^{2}}{x_{R}} \int_{0}^{X} d \theta^{2}=\frac{E_{s}^{2}}{x_{R}} \int_{0}^{X} \frac{d X}{(p \beta)^{2}}
$$

where the integration over $X$ takes into account the change in $p \beta$. For thin foils $(p \beta \approx$ constant $)$

$$
\left\langle\theta^{2}\right\rangle \approx\left(\frac{\mathrm{E}_{\mathrm{s}}^{2}}{\mathrm{p} \beta}\right)^{2} \frac{\Delta \mathrm{X}}{\mathrm{X}_{\mathrm{R}}}
$$

For thick foils, Eq. (3a) can be solved ${ }^{4}$ by approximating the range energy relation by

$$
E=K R^{n}
$$

where $\quad \mathrm{K}$ and $\mathrm{n}$ are constants

$E=$ the kinetic energy $(\mathrm{MeV})$ and

$\mathrm{R}=$ the mean range of the particles in $\mathrm{gm} / \mathrm{cm}^{2}$ 
Then the residual energy after passing through a thickness, $X$ is given by

$$
E_{r}=K(R-X)^{n}
$$

For non-relativistic particles

$$
\mathrm{p} \beta \approx 2 \mathrm{E}_{\mathbf{r}}=2 \mathrm{~K}(\mathrm{R}-\mathrm{X})^{\mathrm{n}}
$$

With this approximation the mean square scatter angle is given substituting $\mathrm{Eq} \cdot$ (5) into Eq. (3a) and integrating ${ }^{4}$

$$
\left\langle\theta^{2}\right\rangle=\frac{E_{S}^{2}}{4 K^{2} x_{R}(2 n-1)}\left[(R-X)^{1-2 n}-R^{1-2 n}\right]
$$

This expression is accurate to better than $10 \%$ below $200 \mathrm{MeV}$ for protons. For a fixed $\left\langle\theta^{2}\right\rangle$ then the energy loss in the thickness $\Delta \mathrm{X}$ is given approximately by

$$
\left.\Delta E \approx \frac{d E}{d X}\right|_{E_{0}} \Delta X=\left.\frac{d E}{d X}\right|_{E_{0}}\left(\frac{E}{p \beta}\right)^{-2} X_{R}\left\langle\theta^{2}\right\rangle
$$

and is proportional to the radiation length times the energy loss rate for the material. Table $I$ lists reasonable values for $n, K, X_{R}$ and the range of values for the relative energy loss $\left(\Delta E / \Delta E_{\mathrm{H}_{2} 0}\right)$ for a fixed $\left\langle\theta^{2}\right\rangle$, possible from different materials. Thus not only can the foil scatter the beam for dose uniformity but a coarse change of the distal edge Bragg peak can result from changes in the foil material. 
Fig. 1 shows the multiple scattering distribution for a single scatter foil. In order that the dose distribution is uniform to $\pm 2.5 \%$ the tumor area must have a radius such that

$$
r \leqslant 0.23 R=0.23 \mathrm{z}\left\langle\theta^{2}\right\rangle 1 / 2
$$

and collimators then eliminate the beam outside this area. The fraction of the beam inside this area is only $5 \%$ of the beam incident on the foil. For sma11 tumor volumes this method can be used but the $95 \%$ of the beam 1 ost in the collimators must have adequate shielding to reduce the radiation from secondary neutron exposure to the patient. Table II lists parameters for two field sizes ( $3 \mathrm{~cm}$ and $8 \mathrm{~cm}$ diameter) for a one meter nozzle length with a dose uniformity of $\pm 2.5 \%$ inside the field volume (efficiency $=5 \%$ ). The quantity $\Delta \mathrm{X}_{\mathrm{H}_{2} \mathrm{O}}$ lists the reduction of the depth of penetration (in $\mathrm{cm}$ of $\mathrm{H}_{2} \mathrm{O}$ ) from the $25.5 \mathrm{~cm}$ penetration depth of the incident $200 \mathrm{MeV}$ beam.

The obvious problem is that for field sizes greater than $3 \mathrm{~cm}$ diameter, the energy loss in the foil reduces the depth of penetration such that the beam is of little use. For fields larger than $3 \mathrm{~cm}$ diameter, the $3 \mathrm{~cm}$ field parameters can be used and the nozzle length scaled in proportion to the field diameter.

III. High Efficiency Nozzles

One way to improve the depth of penetration is to allow the protons to drift further, therefore requiring less energy loss in the scatter foil. However another method using two foils can help reduce the energy loss nd 
increase the efficiency. This method was suggested by Koehler ${ }^{5}$ and uses a beam stop to reduce the intensity in the center of the beam scattered from the first foil and a second foil to fill in the occluded areas.

Fig. 2 shows the arrangement of the foils and beam stops. If the beam distribution from the first foil is

$$
f\left(r_{1}\right) r_{1} d r_{1} d \theta=\frac{1}{\pi R_{1}^{2}} \quad \operatorname{EXP}\left[-\left(\frac{r_{1}}{R_{1}}\right)^{2}\right] r_{1} d r_{1} d \theta
$$

where

$$
\mathrm{R}_{1}=\mathrm{z}_{1}\left\langle\theta_{1}^{2}\right\rangle 1 / 2
$$

then the second scatter foil yields a second and independent divergence $f\left(r_{2}\right)$ such that

$$
\vec{r}=\vec{r}_{1}+\vec{r}_{2} \quad \text { or } \quad \vec{r}_{2}=\vec{r}-\vec{r}_{1}
$$

Now the conditional distribution

$$
f\left(\vec{r}_{1}, \vec{r}_{2}\right)=f\left(\vec{r}_{1}\right) f\left(\vec{r}_{2}\right)
$$

or

$$
\begin{aligned}
f\left(r_{1}, r\right) \operatorname{rdrd} \theta r_{1} d r_{1} d \theta_{1} & =\frac{1}{\left(\pi R_{1} R_{2}\right)^{2}} \operatorname{ExP}\left\{-\left(\frac{r_{1}}{R_{1}}\right)^{2}-\left(\frac{r_{1}^{2}+r^{2}}{R_{2}^{2}}\right)\right. \\
& \left.+\frac{2 r_{1} r}{R_{2}^{2}} \cos \theta\right\} \quad r d r d \theta r_{1} d r_{1} d \theta
\end{aligned}
$$

Integrating over $\vec{r}_{1}$ and $\theta$ yields the net beam distribution function in $r$ 


$$
f(r)=\frac{2}{\pi R_{1}^{2} R_{2}^{2}} \operatorname{EXP}\left[-\left(\frac{r}{R_{2}}\right)^{2}\right]: \int_{A} \operatorname{EXP}\left(-K x^{2}\right) I_{o}\left(\frac{2 X r}{R_{z}}\right) x d x
$$

where

$$
\begin{gathered}
x=\frac{r_{1}}{R_{2}}, \quad K=1+\left(\frac{R_{2}}{R_{1}}\right)^{2} \\
I_{0}(Z)=\frac{1}{\pi} \int_{0}^{\pi} \operatorname{EXP}(Z \cos \theta) d \theta \\
=\text { Bessel Function } I_{0}
\end{gathered}
$$

The integration in Eq. (10) is over the disconnected region, A, where the beam is not stopped by the beam stops, i.e., the integration is for

$$
0 \leqslant r_{1} \leqslant A_{0} \quad \text { and } \quad A_{1} \leqslant r_{1} \leqslant A_{2}
$$

where $\quad A_{0}, A_{1}$ and $A_{2}$ are the projected radii of the beam stops on the entrance portal.

Equation (10) can be solved assuming values for $R_{1}, R_{2}, A_{0}, A_{1}$ and $A_{2}$. Since $A_{1}$ will set the approximate dimension of the uniform dose region, it is convenient to scale $R_{1}, R_{2}, A_{0}$ and $A_{2}$ by $A_{1}$. The uniform dose region can then be defined in units of $A_{1}$. When an optimum choice of these parameters is found $A_{1}$ can be scaled such that the uniform dose region corresponds to the tumor area to be covered. Finally the choice of $z_{1}$ and $z_{2}$ can be made to yield a reasonable depth of penetration by reducing the foil thickness. Fig. 3 and 4 show the dose distribution and beam efficiency distribution for two 
choices of $R_{1}, R_{2}, A_{0}$ and $A_{2}$. Fig. 3 uses a solid inner beam stop (i.e., $A_{0}=$ $a_{0}=0$ ) and yields a dose uniformity of $\pm 2.5 \%$ for $r \leqslant 1.2 A_{1}$, and an efficiency of $14 \%$. By opening a small hole in the inner beam stop (i.e., $A_{0} \neq$ 0 ) increased beam efficiency can be obtained. Fig. 4 demonstrates this type of nozzle, which has a dose uniformity of $\pm 2.5 \%$ for $r \leqslant 1.45 \mathrm{~A}_{1}$ and an efficiency of $27 \%$. Although other parameters might improve this efficiency slightly, this nozzle design is quite adequate. Table III lists the parameters for the nozzle shown in Fig. 4 for various field sizes of the \pm $2.5 \%$ dose uniformity region. The distances assumed for the nozzles described in Table III are $z_{1}=5$ meters and $z_{2}=4$ meters. The different materials used for the scattering foils offer a wide range of penetration depths. Additional variations in penetration depth is possible by changing material of only one of the two foils.

For the small field volumes a two scattering foil nozzle, as shown in Fig. 4, can be used but with a shorter nozzle length than shown in Table III. Table IV shows such nozzle parameters for small fields $(\leqslant 20 \mathrm{~cm}$ diameter) with $\mathrm{z}_{1}=2$ meters and $\mathrm{z}_{2}=1$ meter. Although the smaller fields can be obtained by collimating the tumor area to be treated at the patient, the nozzles described in Table IV yield higher efficiency and reduced scatter dose from secondary neutrons off the collimators.

IV. Construction and Use of the High Efficiency Proton Nozzles

The actual use of these nozzles will be to choose a field size which yields adequate coverage of the tumor area, yet small enough to yield a reasonable dose rate. Then a beam stopping collimator (thickness $=2.5^{\prime \prime} \mathrm{Fe}$ or 
$2 " \mathrm{~Pb})$ with hole radii given by Table III or IV $\left(a_{0}, a\right.$, and $\left.a_{2}\right)$ is inserted at the second scatter foil position. After the treatment plan has prescribed the distal edge of the tumor to be treated, the scatter foil material, given by Table III or IV, is chosen to yield a distal Bragg peak greater than or equal to the distal edge of the tumor. Finally the actual tumor area is defined by a collimator just ahead of the patient and a bolus shapes the field depth to account for the geometrical contour and inhomogeneities within the field volume. Scanning of the Bragg peak through the depth of the tumor, in order to yield a uniform dose to the tumor, will be achieved by varying the material ahead of the bolus during the exposure. This can be achieved by a range wheel, descrete range absorbers or an infinitely variable water absorber. 


\section{References}

1. Tatsuaki Kanai et al., "Spot Scanning System for Proton Therapy" Medical Physics 7, 365 (1980).

2. E. V. Hungerford et al., "Proton Small Angle Multiple Scattering at 600 MeV," Nuclear Physics Al97, 515 (1972).

3. V. L. Highland, "Some Practical Remarks on Multiple Scattering," Nuc. Inst. and Methods 129, 497 (1975).

4. S. L. Kramer, "Physics of Charged Particle Radiography" work in progress.

5. A. M. Koehler et al., "Flattening of Proton Dose Distributions for Large-Field Radiotherapy" Medical Physics 4, 297 (1977). 
Table I. Parameters for Range-energy and Multiple Scattering of Protons

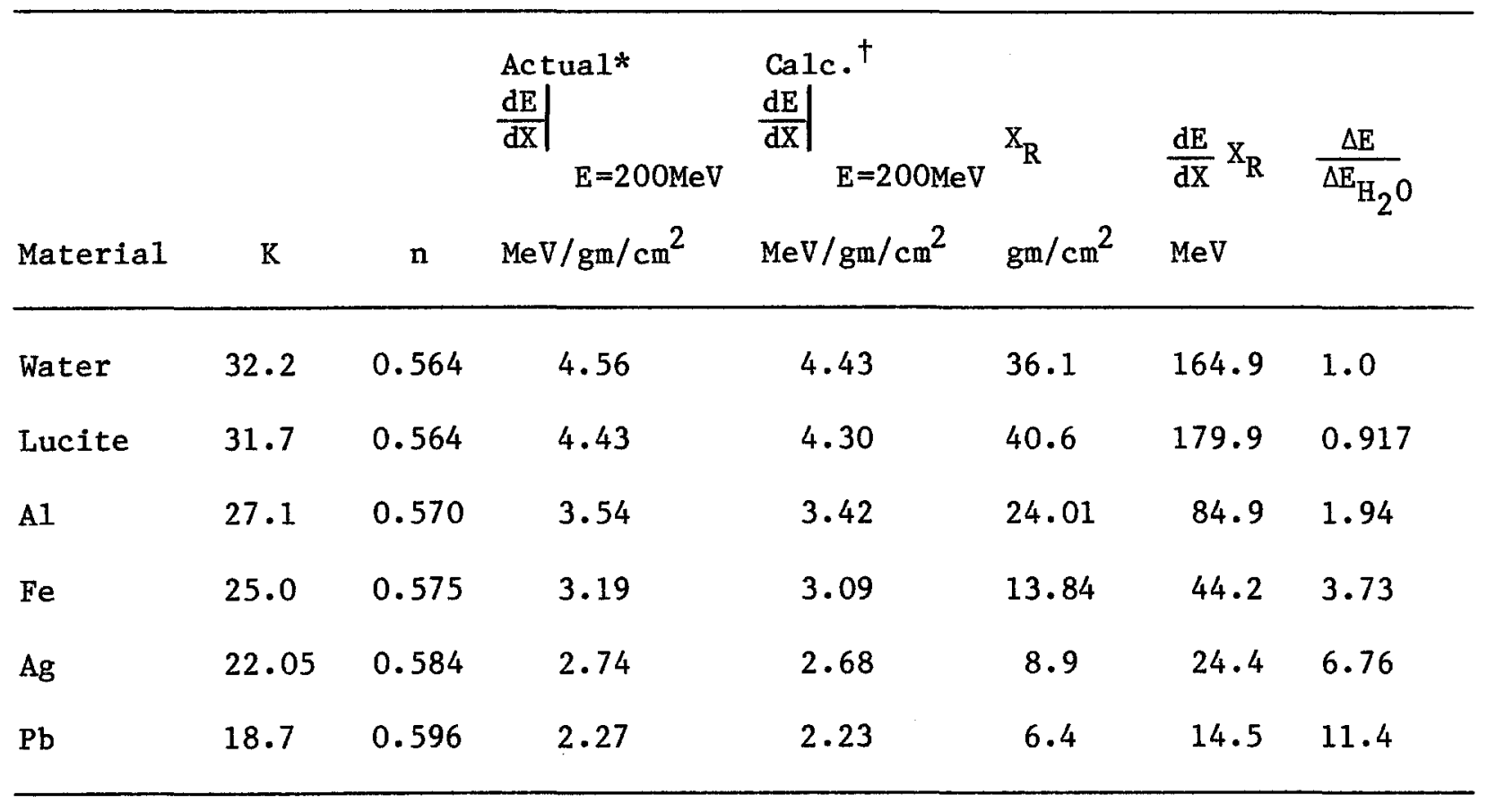

\footnotetext{
*Energy loss for $200 \mathrm{MeV}$ protons taken from W. H. Barkas and M. J. Berger in "Studies in Penetration of charged Particles in Matter," National Academy of Sciences, Nuclear Science Series Report \# 39 (1964).

${ }^{\dagger}$ Calculated energy loss from differentiating Eq. (4).
} 
Table II. Parameters for Single Scatter Foil Proton Nozzle* (1 meter long)

\begin{tabular}{|c|c|c|c|c|c|c|c|c|c|}
\hline $\begin{array}{r}\text { Field } \\
\text { Size }\end{array}$ & & & $\phi F i$ & $1 d$ & & $8 \mathrm{c}$ & $\phi$ Fiel & & \\
\hline Param. & Lucite & $\mathrm{A} 1$ & $\mathrm{Fe}$ & $\mathrm{Pb}$ & Lucite & $\mathrm{A} 1$ & $\mathrm{Fe}$ & $\mathrm{Pb}$ & Units \\
\hline$\left\langle\theta^{2}\right\rangle, 1 / 2$ & 65 & 65 & 65 & 65 & 174 & 174 & 174 & 174 & mrad \\
\hline $\mathrm{X}$ & 23.9 & 22.6 & 16.9 & 9.7 & 26.2 & 33.2 & 36.0 & 38.5 & $\mathrm{gm} / \mathrm{cm}^{2}$ \\
\hline $\mathrm{L}$ & 199 & 83.6 & 21.4 & 8.5 & 222 & 123 & 45.8 & 33.9 & $\mathrm{~mm}$ \\
\hline$\Delta \mathrm{E}$ & 144 & 95.0 & 58.7 & 22.5 & 199 & 192 & 172 & 106 & $\mathrm{MeV}$ \\
\hline$\Delta \mathrm{x}_{\mathrm{H}_{2}} 0$ & 22.7 & 17.0 & 11.7 & 4.9 & 25.4 & 25.4 & 24.7 & 18.9 & $\mathrm{~cm}$ \\
\hline $\begin{array}{l}\mathrm{dE} / \mathrm{dX} \\
\text { Front }\end{array}$ & 11.91 & 7.3 & 5.8 & 4.9 & 280 & 54.5 & 20.4 & 8.0 & $\mathrm{MeV} / \mathrm{gm} / \mathrm{cm}^{2}$ \\
\hline$\star_{\mathrm{Z} 1}=1$ & meter, $E_{0}$ & $=200$ & leV, $\mathrm{dE}$ & $d x)_{E=}$ & $=4.431$ & $\mathrm{MeV} / \mathrm{gm} /$ & $\begin{array}{l}n^{2} \text {; eff } \\
\text { uni }\end{array}$ & $\begin{array}{l}\text { iency }= \\
\text { rmity }\end{array}$ & $5 \%+2.5 \%$ \\
\hline$X, L$ & $=$ thickr & iess of & scatter & foil & $\mathrm{ngm} / \mathrm{cm}^{2}$ & , mm res & pective & & \\
\hline$\Delta \mathrm{E}$ & $=$ energy & lost & n foil & & & & & & \\
\hline$\Delta \mathrm{X}_{\mathrm{H}_{2} 0}$ & $\begin{array}{l}=\text { reduct } \\
\mathrm{H}_{2} \mathrm{O}\end{array}$ & ion of & depth & f pene & cation of & beam $f_{3}$ & om the & Initial & $25.49 \mathrm{~cm} \mathrm{of}$ \\
\hline $\mathrm{dE} / \mathrm{dX}=$ & linear & energy & ansfe & at $t$ & entranc & portal & & & \\
\hline
\end{tabular}


Table III. Parameters for the High Efficiency-Large Field Proton Nozzle*

\begin{tabular}{|c|c|c|c|c|c|c|c|c|c|c|c|c|c|c|c|c|c|}
\hline Field & $8 c$ & $\operatorname{cm} \phi$ & & & 20 & $\mathrm{~cm} \phi$ & & & 30 & $\mathrm{~cm} \phi$ & & & & $5 \mathrm{~cm} \phi$ & & & \\
\hline $\begin{array}{l}\theta_{1}(\mathrm{mr}) \\
\theta_{2}(\mathrm{mr})\end{array}$ & $\begin{array}{l}9 \\
6\end{array}$ & $\begin{array}{l}9 \\
6\end{array}$ & $\begin{array}{l}9 \\
6\end{array}$ & $\begin{array}{l}9 \\
6\end{array}$ & $\begin{array}{l}23 \\
14\end{array}$ & $\begin{array}{l}23 \\
14\end{array}$ & $\begin{array}{l}23 \\
14\end{array}$ & $\begin{array}{l}23 \\
14\end{array}$ & $\begin{array}{l}35 \\
21\end{array}$ & $\begin{array}{l}35 \\
21\end{array}$ & $\begin{array}{l}35 \\
21\end{array}$ & $\begin{array}{l}35 \\
21\end{array}$ & $\begin{array}{l}53 \\
31\end{array}$ & $\begin{array}{l}53 \\
31\end{array}$ & $\begin{array}{l}53 \\
31\end{array}$ & $\begin{array}{l}53 \\
31\end{array}$ & $\mathrm{mrad}$ \\
\hline $\begin{array}{ll}\mathrm{X} 1 & \mathrm{gm} / \mathrm{cm}^{2} \\
\mathrm{~L} 1 \mathrm{~mm}\end{array}$ & $\begin{array}{l}1.39 \\
11.7\end{array}$ & $\begin{array}{l}0.83 \\
3.1\end{array}$ & $\begin{array}{l}0.48 \\
0.6\end{array}$ & $\begin{array}{l}0.23 \\
0.2\end{array}$ & $\begin{array}{l}7.43 \\
63\end{array}$ & $\begin{array}{l}4.83 \\
17.9\end{array}$ & $\begin{array}{l}2.91 \\
3.7\end{array}$ & $\begin{array}{l}1.39 \\
1.2\end{array}$ & $\begin{array}{l}13.6 \\
115\end{array}$ & $\begin{array}{l}9.8 \\
36\end{array}$ & $\begin{array}{l}6.18 \\
7.8\end{array}$ & $\begin{array}{l}3.06 \\
2.7\end{array}$ & $\begin{array}{l}20.7 \\
175\end{array}$ & $\begin{array}{l}17.7 \\
65.7\end{array}$ & $\begin{array}{l}12.2 \\
15.6\end{array}$ & $\begin{array}{l}6.59 \\
5.8\end{array}$ & $\underset{\mathrm{mm}}{\mathrm{gm} / \mathrm{cm}^{2}}$ \\
\hline $\begin{array}{l}\mathrm{X} 2 \mathrm{gm} / \mathrm{cm} \\
\mathrm{L} 2 \mathrm{~mm}\end{array}$ & $\begin{array}{l}0.46 \\
3.9\end{array}$ & $\begin{array}{l}0.28 \\
1.0\end{array}$ & $\begin{array}{l}0.17 \\
0.2\end{array}$ & $\begin{array}{l}0.08 \\
0.1\end{array}$ & $\begin{array}{l}1.99 \\
16.9\end{array}$ & $\begin{array}{l}1.48 \\
5.5\end{array}$ & $\begin{array}{l}0.94 \\
1.2\end{array}$ & $\begin{array}{l}0.47 \\
0.4\end{array}$ & $\begin{array}{l}2.67 \\
22.6\end{array}$ & $\begin{array}{l}2.59 \\
9.6\end{array}$ & $\begin{array}{l}1.86 \\
2.4\end{array}$ & $\begin{array}{l}1.00 \\
0.9\end{array}$ & $\begin{array}{l}2.08 \\
17.6\end{array}$ & $\begin{array}{l}3.39 \\
122.7\end{array}$ & $\begin{array}{l}3.11 \\
4.0\end{array}$ & $\begin{array}{l}2.05 \\
1.8\end{array}$ & $\underset{\mathrm{mm}}{\mathrm{gm} / \mathrm{cm}^{2}}$ \\
\hline$\Delta \mathrm{E}(\mathrm{MeV})$ & 8.1 & 3.8 & 2.0 & 0.7 & 44.5 & 22.6 & 12.2 & $4 \cdot 18$ & 84.2 & 46.5 & 26.1 & 9.24 & 136 & 87.2 & 53.0 & 20.0 & $\mathrm{MeV}$ \\
\hline $\begin{array}{ll}\Delta \mathrm{X} & \mathrm{cm} \\
\text { of } & \mathrm{H}_{2} \mathrm{O}\end{array}$ & 1.8 & 0.86 & 0.45 & 0.15 & 9.2 & $4 \cdot 9$ & 2.7 & 0.94 & 15.8 & 9.55 & 5.6 & 2.05 & 22.2 & $16 \cdot 3$ & 10.7 & 4.35 & $\mathrm{cmH}_{2} \mathrm{O}$ \\
\hline $\begin{array}{l}\mathrm{dE} / \mathrm{dX} \\
\text { Front }\end{array}$ & 4.57 & 4.49 & $4 \cdot 46$ & $4 \cdot 44$ & $5 \cdot 37$ & 4.85 & 4.65 & 4.50 & 6.75 & 5.43 & 4.93 & 4.59 & 10.7 & 6.89 & 5.61 & 4.80 & $\mathrm{MeV}-\mathrm{cm}^{3} / \mathrm{gm}$ \\
\hline & & $\begin{array}{r}27.5 \\
5.5\end{array}$ & & & & $\begin{array}{l}68.9 \\
13.8\end{array}$ & & & & $\begin{array}{r}103.4 \\
20.7\end{array}$ & & & & $\begin{array}{r}155.2 \\
31.0\end{array}$ & & & $\begin{array}{l}\mathrm{mm} \\
\mathrm{mm}\end{array}$ \\
\hline $\begin{array}{l}A_{0} \\
a_{0}\end{array}$ & & $\begin{array}{r}11.6 \\
2.3\end{array}$ & & & & $\begin{array}{r}29.0 \\
5.8\end{array}$ & & & & $\begin{array}{r}43.4 \\
8.7\end{array}$ & & & & $\begin{array}{l}65.2 \\
13.0\end{array}$ & & & $\frac{\mathrm{mm}}{\mathrm{mm}}$ \\
\hline $\begin{array}{l}A_{2} \\
a_{2}\end{array}$ & & $\begin{array}{r}110.0 \\
22.0\end{array}$ & & & & $\begin{array}{r}275.6 \\
55.2\end{array}$ & & & & $\begin{array}{r}413.6 \\
82.8\end{array}$ & & & & $\begin{array}{l}620.8 \\
124.0\end{array}$ & & & $\mathrm{~mm}$ \\
\hline
\end{tabular}

$* \mathrm{Z}_{1}=5$ meters, $\mathrm{Z}_{2}=4$ meters, Effic $=27 \%$ for $\pm 2.5 \%$ dose uniformity

$\left.\mathrm{E}_{\text {Beam }}=200 \mathrm{MeV} \mathrm{dE} / \mathrm{dX}\right)_{\text {Beam }}=4.43 \mathrm{MeV} / \mathrm{gm} / \mathrm{cm}^{2} \mathrm{H}_{2} \mathrm{O}$

Range $\left(\mathrm{H}_{2} \mathrm{O}\right)=25.49 \mathrm{~cm}$ 
Table IV. Parameters for the High Efficiency - Small Field Proton Nozzle*

\begin{tabular}{|c|c|c|c|c|c|c|c|c|c|c|c|c|c|}
\hline $\begin{array}{r}\text { Field } \\
\text { size }\end{array}$ & & $3 \mathrm{~cm} \phi$ & & & & $8 c$ & $\mathrm{~m} \phi$ & & & & $0 \mathrm{~cm} \phi$ & & \\
\hline Param. & Lucite & $\mathrm{A} 1$ & $\mathrm{Fe}$ & $\mathrm{Pb}$ & Lucite & $\mathrm{A} 1$ & $\mathrm{Fe}$ & $\mathrm{Pb}$ & Lucite & $\mathrm{A} 1$ & $\mathrm{Fe}$ & $\mathrm{Pb}$ & Units \\
\hline $\begin{array}{l}\theta_{1} \\
\theta_{2}\end{array}$ & & & $\begin{array}{l}9 \\
8\end{array}$ & & & & $\begin{array}{l}23 \\
22\end{array}$ & & & $\begin{array}{l}5 \\
5\end{array}$ & $\begin{array}{l}9 \\
5\end{array}$ & & $\begin{array}{l}\text { mrad } \\
\text { mrad }\end{array}$ \\
\hline $\begin{array}{l}\mathrm{x}_{1} \\
\mathrm{~L}_{1}\end{array}$ & $\begin{array}{l}1.22 \\
10.4\end{array}$ & $\begin{array}{l}0.73 \\
2.7\end{array}$ & $\begin{array}{l}0.43 \\
0.54\end{array}$ & $\begin{array}{l}0.20 \\
0.17\end{array}$ & $\begin{array}{l}7.4 \\
62.9\end{array}$ & $\begin{array}{l}4.83 \\
17.9\end{array}$ & $\begin{array}{l}2.91 \\
3.7\end{array}$ & $\begin{array}{l}1.39 \\
1.22\end{array}$ & $\begin{array}{l}22.2 \\
189\end{array}$ & $\begin{array}{l}20.2 \\
74.6\end{array}$ & $\begin{array}{l}14.5 \\
18.4\end{array}$ & $\begin{array}{l}8.0 \\
7.0\end{array}$ & $\underset{\mathrm{mm}}{\mathrm{gm} / \mathrm{cm}^{2}}$ \\
\hline $\begin{array}{l}\mathrm{X}_{2} \\
\mathrm{~L}_{2}\end{array}$ & $\begin{array}{l}1.03 \\
8.7\end{array}$ & $\begin{array}{l}0.63 \\
2.3\end{array}$ & $\begin{array}{l}0.37 \\
0.50\end{array}$ & $\begin{array}{l}0.17 \\
0.20\end{array}$ & $\begin{array}{l}4.6 \\
39.3\end{array}$ & $\begin{array}{l}3.6 \\
13.4\end{array}$ & $\begin{array}{l}2.36 \\
3.0\end{array}$ & $\begin{array}{l}1.19 \\
1.0\end{array}$ & $\begin{array}{l}2.96 \\
25.1\end{array}$ & $\begin{array}{l}6.84 \\
25.3\end{array}$ & $\begin{array}{l}7.62 \\
9.7\end{array}$ & $\begin{array}{l}5.91 \\
5.2\end{array}$ & $\begin{array}{l}\mathrm{gm} / \mathrm{cm}^{2} \\
\mathrm{~mm}\end{array}$ \\
\hline$\stackrel{\Delta \mathrm{E}}{\Delta \mathrm{X}_{\mathrm{H}_{2} 0}}$ & $\begin{array}{l}9.9 \\
2.2\end{array}$ & $\begin{array}{l}4.7 \\
1.06\end{array}$ & $\begin{array}{l}2.48 \\
0.56\end{array}$ & $\begin{array}{l}0.83 \\
0.2\end{array}$ & $\begin{array}{l}58.8 \\
11.7\end{array}$ & $\begin{array}{l}30.7 \\
6.53\end{array}$ & $\begin{array}{l}16.8 \\
3.67\end{array}$ & $\begin{array}{l}5.82 \\
1.30\end{array}$ & $\begin{array}{l}122 \\
24.5\end{array}$ & $\begin{array}{l}122 \\
20.7\end{array}$ & $\begin{array}{l}80.8 \\
15.3\end{array}$ & $\begin{array}{l}32.9 \\
6.9\end{array}$ & $\begin{array}{l}\mathrm{MeV} \\
\mathrm{cm} \mathrm{H} \mathrm{H}_{2} \mathrm{O}\end{array}$ \\
\hline $\mathrm{dE} / \mathrm{dX}$ & 4.6 & 4.5 & 4.47 & 4.4 & 5.8 & 5.03 & 4.74 & 4.53 & 18.2 & 9.2 & 6.6 & 5.1 & $\mathrm{MeV}-\mathrm{cm}^{3} / \mathrm{g}$ \\
\hline $\begin{array}{l}A_{0} \\
A_{1} \\
A_{2}\end{array}$ & & $\begin{array}{l}0.4 \\
1.0 \\
4.1\end{array}$ & & & & & $\begin{array}{l}1.15 \\
2.82 \\
11.03\end{array}$ & & & & $\begin{array}{l}.90 \\
.90 \\
7.6\end{array}$ & & $\begin{array}{l}\mathrm{cm} \\
\mathrm{cm} \\
\mathrm{cm}\end{array}$ \\
\hline $\begin{array}{l}a_{0} \\
a_{1} \\
a_{2}\end{array}$ & & $\begin{array}{l}2.1 \\
5.2 \\
20 .\end{array}$ & & & & & $\begin{array}{l}.5 \\
3.8 \\
55.2\end{array}$ & & & & $\begin{array}{l}3.8 \\
4.5 \\
38\end{array}$ & & $\begin{array}{l}\mathrm{mm} \\
\mathrm{mm} \\
\mathrm{mm}\end{array}$ \\
\hline
\end{tabular}

${ }^{*} \mathrm{z}_{1}=2 \mathrm{~m}, \mathrm{z}_{2}=1 \mathrm{~m}$, Effic. $=27 \%$ for $\pm 2.5 \%$ dose uniformity

$\mathrm{E}_{\text {Beam }}=200 \mathrm{MeV}, \mathrm{dE} / \mathrm{dX}=4.43 \mathrm{MeV}-\mathrm{cm}^{2} / \mathrm{gm}$, Range $\left(\mathrm{H}_{2} \mathrm{O}\right)=25.49 \mathrm{~cm}$ 


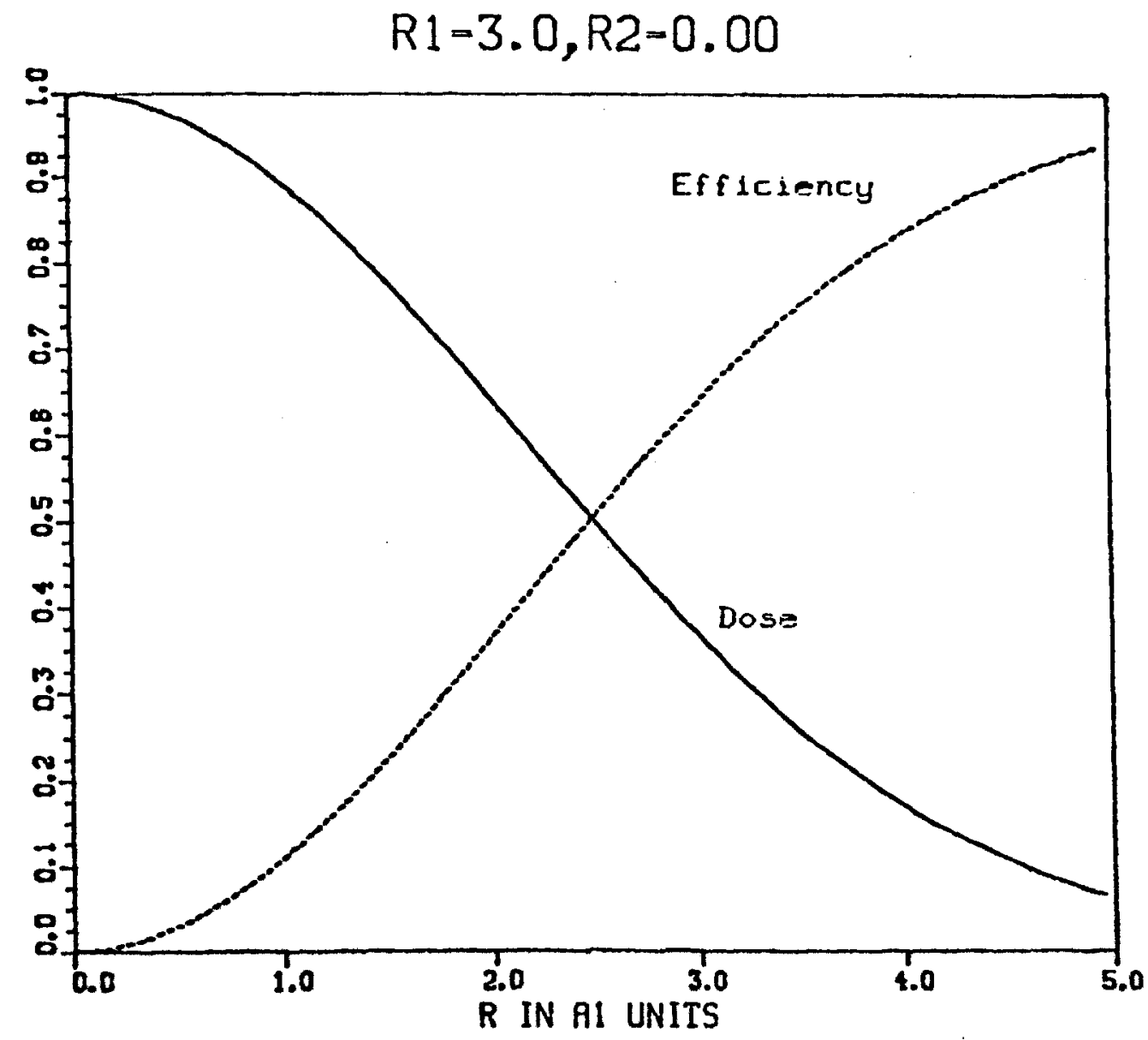

Fig. 1 Dose Distribution and Beam Efficiency for a single scatter foil proton nozzle (rms radius of the beam distribution $=3.0)$. 


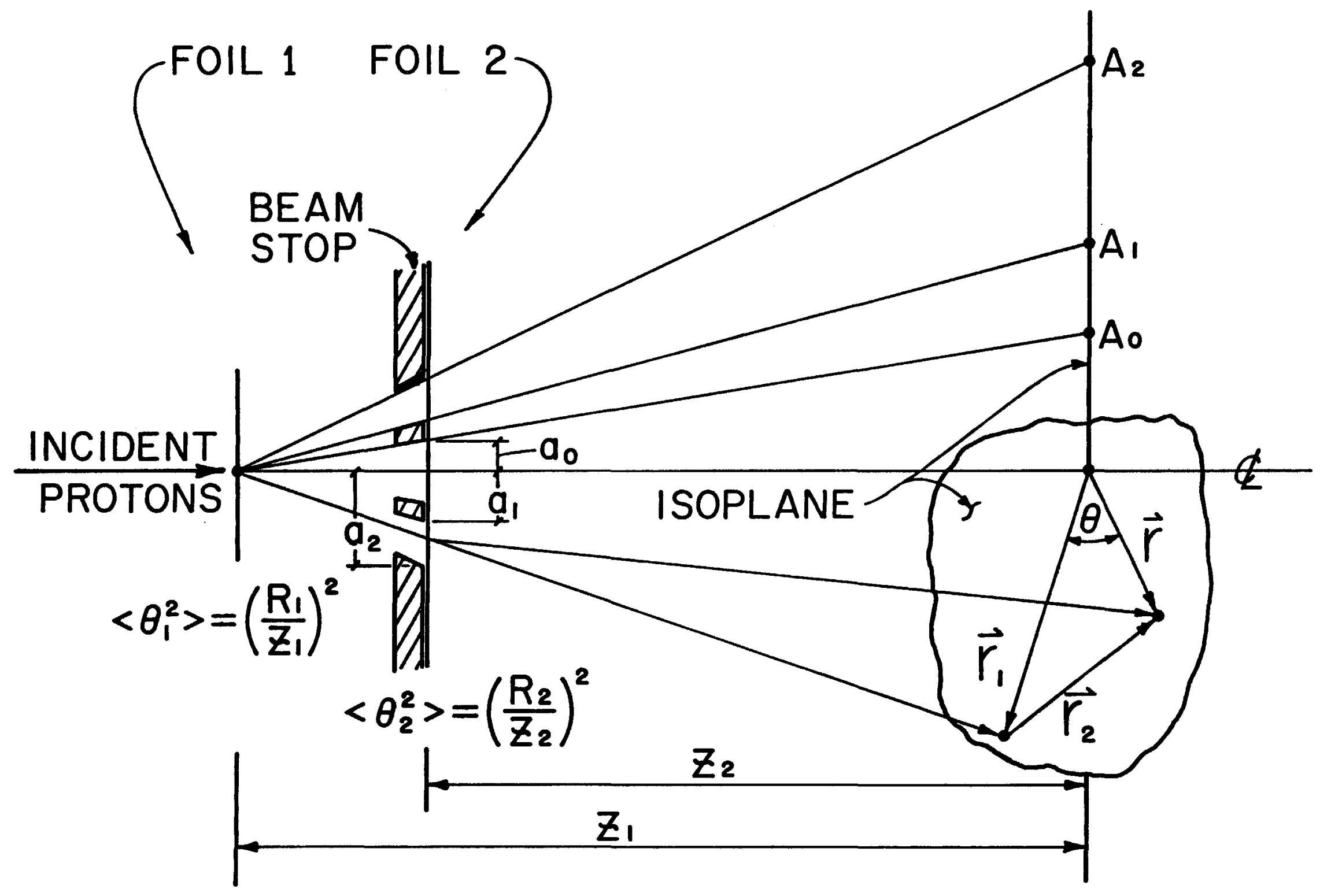

Fig. 2 Layout for a high efficiency nozzle. 


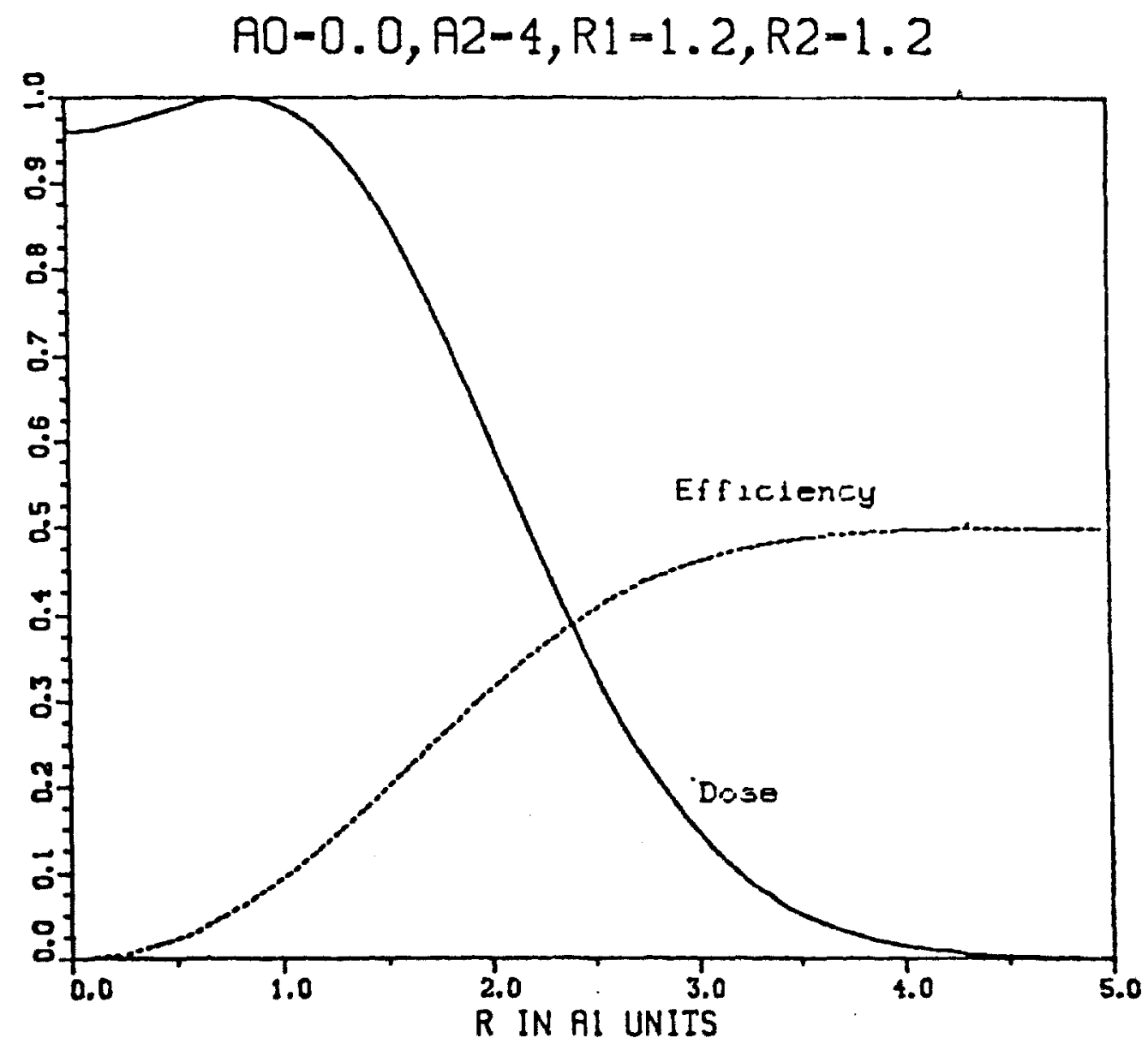

Fig. 3 proton nozzle with two scattering foils and a solid inner beam stop. 


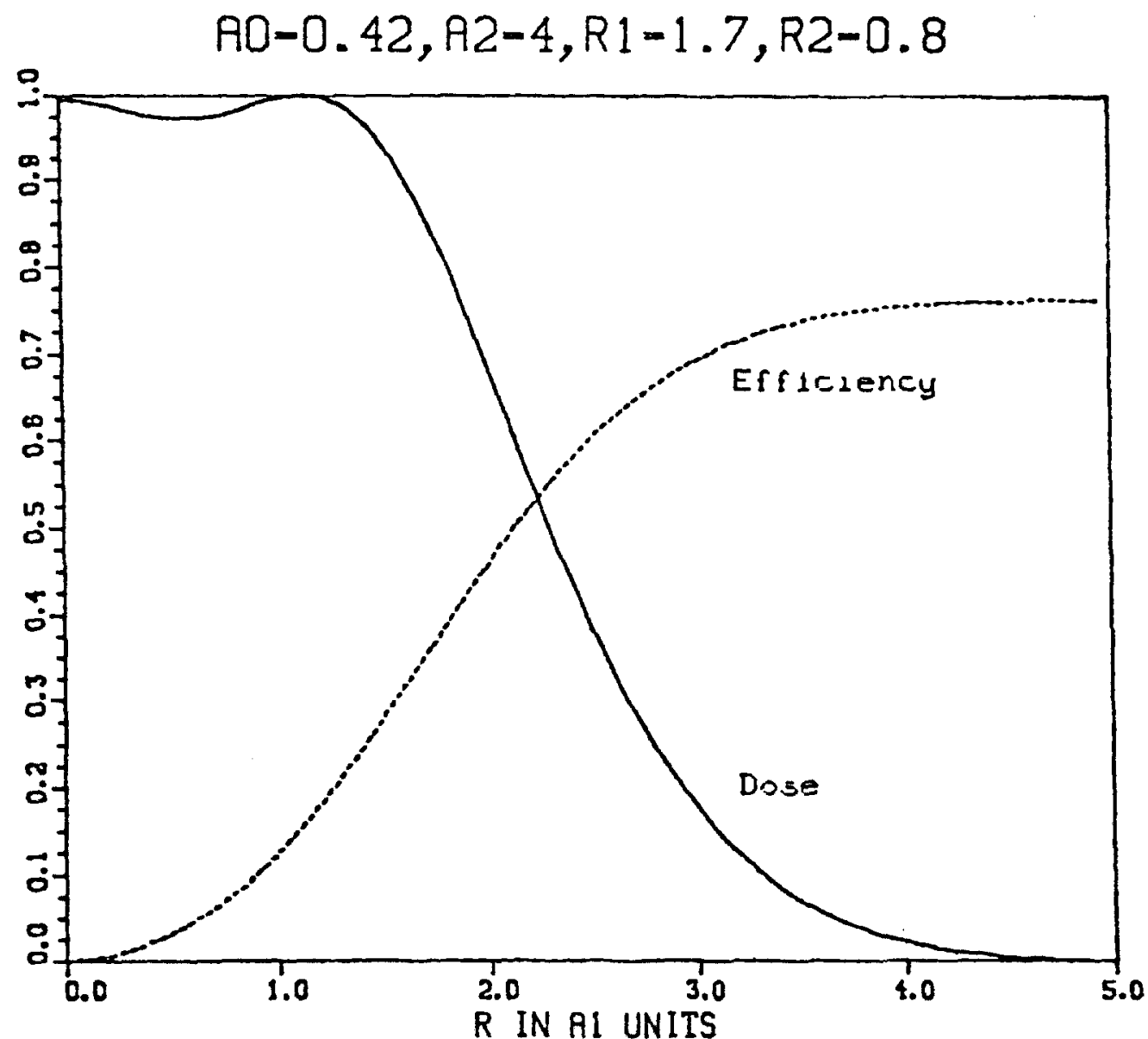

Fig. 4 High efficiency proton nozzle using two scattering foils. 